\title{
Gerak Tari Kreasi melalui Regio Emilia Approach untuk Meningkatkan Kecerdasan Sosial dan Emosional Anak di Gorontalo
}

\author{
Pupung Puspa Ardini, Milawati Eki \\ Universitas Negeri Gorontalo \\ milawatyeki12@gmail.com
}

\begin{tabular}{l}
\hline Info Artikel \\
\hline Sejarah Artikel: \\
Diterima (Desember) (2019) \\
Disetujui (Januari) (2019) \\
Dipublikasikan (januari) \\
(2019) \\
\hline Keywords: \\
Gerak Tari, Tari Kreasi, \\
region Emilia Approach, \\
Kecerdasan, Sosial dan \\
Emosional, Anak Usia \\
Dini
\end{tabular}

\begin{abstract}
Abstrak
Tujuan dari penelitian ini adalah untuk mengetahui peningkatan kecerdasan sosial anak-anak kelompok B di TK Gorontalo dari Wali Kota melalui kreasi gerak tari dengan Pendekatan Regio Emilia dan mengetahui peningkatan kecerdasan emosi anak. Metode penelitian ini menggunakan Penelitian Tindakan Kelas (PTK). Karakteristik subjek penelitian adalah anak-anak berusia 5-6 tahun. Pengumpulan data dilakukan dengan pedoman observasi tindakan. Data yang dikumpulkan dianalisis secara statistik menggunakan persentase dari beberapa aspek yang telah ditentukan. Hasil penelitian ini menunjukkan bahwa (1) pada siklus pertama, kecerdasan sosial anak dari 20 orang yang menyelesaikan sebanyak ays 11 orang atau 55\% dan mereka yang belum tuntas adalah 9 orang atau 45\%, sedangkan aspek dari kecerdasan emosi anak lengkap sebanyak 9 orang atau 45\% dan yang belum selesai 11 orang atau 55\%. Pada siklus kedua, kecerdasan sosial anak-anak dari 20 orang yang menyelesaikan sebanyak 16 orang atau $80 \%$ dan mereka yang belum selesai adalah 4 orang atau 20\%, sedangkan pada aspek kecerdasan emosional anak-anak 20 orang menyelesaikan sebanyak sebanyak 17 orang atau $85 \%$ dan yang belum selesai adalah 3 orang atau 15\%. Ada peningkatan persentase (\%) dari keberhasilan siklus pertama siklus II, terutama pada aspek kecerdasan sosial anak dari 55\% menjadi 80\%. Peningkatan terjadi sebesar $25 \%$ setelah melakukan berbagai refleksi atas tindakan pembelajaran. Sedangkan pada aspek kecerdasan emosi dari siklus I ke siklus II terjadi peningkatan sebesar 30\%, dari 55\% menjadi $85 \%$.
\end{abstract}

\begin{abstract}
The purpose of this research is to know the increase in social intelligence of group $B$ children in the Gorontalo Kindergarten of the Trustees of the City through dance moves creations with the Regio Emilia Approach and find out the increase in emotional intelligence children. The characteristics of the research subjects were children aged 5-6 years. Data collection is carried out by action observation guidelines. The collected data are analyzed statistically using a percentage of several predetermined aspects. The results of this study indicate that (1) in the first cycle, the social intelligence of children from 20 people who completed as many ays 11 people or 55\% and those who have not finished are 9 people or 45\%, while the aspects of children's emotional intelligence are complete as many as 9 people or $45 \%$ and the unfinished is 11 people or 55\%. In the second cycle, the social intelligence of children from 20 people who completed as many as 16 people or $80 \%$ and those who have not finished are 4 people or 20\%, while in the emotional intelligence aspects of children of 20 people completed as many as 17 people or $85 \%$ and those who have not finished are 3 people or $15 \%$. There is an increase in the percentage (\%) of the success of the first cycle of cycle II, especially on aspects of child
\end{abstract}


social intelligence from 55\% to $80 \%$. The increase occurred by $25 \%$ after doing various reflections on learning actions. Whereas in the aspect of emotional intelligence from cycle I to cycle II there was an increase of 30\%, from 55\% to $85 \%$.

(C) 2019 Pupung Puspa Ardini, Milawati Eki Under the license CC BY-SA 4.0

\section{Pendahuluan}

Pendidikan anak usia dini merupakan proses belajar yang paling mendasar dan menempati posisi yang sangat strategis untuk pengembangan berbagai kecerdasan yang dimiliki oleh anak. Pendidikan gerak tari kreasi merupakan suatu proses gerakan nyata dan bertujuan untuk mendidik dan melatih anak agar mampu mengontrol gerak tubuh, dan mengharmonisasikan antara gerak tubuh dan pikiran. Melalui gerak tari kreasi, aspek kecerdasan anak secara perlahan-lahan dapat dikembangkan dengan baik. Oleh karena itu, dalam memberikan pendidikan tari anak usia dini diperlukan penekanan pada keharmonisan gerak, dan pengontrolan gerak motorik kasar maupun pengontrolan gerak motorik halus. Gerak tari kreasi dilakukan melalui gerak tari yang diekspresikan melalui perasaan dan diubah oleh imajinasi dan diberi bentuk oleh media gerak sehingga menjadi bentuk gerak simbolis yang sempurna.

Perkembangan emosional anak merupakan suatu tahapan yang perlu mendapat perhatian, pemahaman, dan bimbingan yang melekat.Guru harus memiliki kemampuan untuk mengontrol emosional anak. Menurut Gardner (2003:48) menyatakan bahwa "kecerdasan emosional adalah kecerdasan antar pribadi (interpersonal) dan kecerdasan intra pribadi (intrapersonal). Kecerdasan antar pribadi yaitu berhubungan dengan kemampuan untuk bisa mengerti dan menghadapi perasaan orang lain. Sedangkan kecerdasan intra pribadi (intrapersonal) merupakan kemampuan untuk memahami dan menguasai diri sendiri".

Banyak metode pembelajaran yang dapat dipakai di dalam proses pembelajaran pada PAUD. Metode-metode tersebut dipakai dalam proses pembelajaran dengan tujuan agar anak mampu memahami pelajaran dan belajar berdasarkan kebiasaan dan 
lingkungan sekitarnya. Dalam penelitian kali ini, metode yang akan dilakukan dalam rangka pembelajaran adalah Regio Emilia Approach.

Dari hasil observasi yang dilakukan oleh peneliti terhadap kecerdasan sosial dan kecerdasan emosional anak Kelompok B pada TK Negeri Pembina Kota Gorontalo dikemukakan bahwa pada indikator kecerdasan sosial anak terdapat 4 orang atau 20\% mampu untuk bekerjasama, 3 orang atau 15\% mampu untuk disiplin, 6 orang atau 25\% mampu percaya diri, dan 6 orang atau 30\% mampu mandiri. Dari persentase (\%) tersebut, maka dapat disimpulkan bahwa dari empat indikator tersebut masih perlu ditingkatkan karena pada persentase jumlah anak yang dikategorikan mampu masih sangat minim. Secara rata-rata anak mencapai kategori "Mampu" hanya mencapai $22,5 \%$.Sejalan dengan itu, pada indikator kecerdasan emosional anak yang dimiliki pada kegiatan seni tari

Pada indikator kecerdasan sosial anak terdapat 2 orang atau 10\% mampu memiliki kesadaran, 4 orang atau 20\% mampu memiliki motivasi, 6 orang atau 30\% mampu memiliki empati, dan 7 orang atau 35\% mampu memiliki pengaturan diri. Dari persentase (\%) di atas, maka dapat disimpulkan bahwa dari empat indikator tersebut masih perlu ditingkatkan karena pada persentase (5) jumlah anak yang dikategorikan mampu masih sangat minim. Secara rata-rata anak yang mencapai kategori "Mampu" hanya mencapai $23,75 \%$.

Berdasarkan latar belakang di atas, maka rumusan masalah yang penulis kaji dalam penelitian ini dirumuskan sebagai berikut : 1 . Apakah implementasi gerak tari kreasi melalui Regio Emilia Approachdapat meningkatkan kecerdasan sosial anak Kelompok B pada TK Negeri Pembina Kota Gorontalo? 2. Apakah implementasi gerak tari kreasi melalui Regio Emilia Approach dapat meningkatkan Kecerdasan Emosional Anak Kelompok B pada TK Negeri Pembina Kota Gorontalo? Beberapa langkah yang perlu dilakukan agar anak mampu mencapai tujuan yang diinginkan antara lain: 1. Menyiapkan Rencana Pelaksanaan Pembelajaran (RPP) yang disesuaikan dengan tema dari pembelajaran yang ditempuh, 2. Menyiapkan alat atau bahan yang diperlukan guna pelaksanaan kegiatan seni tari kreasi tersebut, 3. Memastikan kesiapan anak dalam proses pembelajaran dengan baik, 4. Menjelaskan peragaan seni tari kreasi tersebut kepada anak dengan cara mencontohkan, 5. Mengatur posisi anak dengan baik agar 
pelaksanaan tari dapat tercapai dengan baik, 6. Melakukan pembimbingan serta arahan terhadap anak agar mereka mampu melakukan gerakan dengan baik dan sempurna.

\section{Metode Penelitian}

Penelitian ini dilaksanakan di kelompok B TK Negeri Pembina Kota Gorontalo. Penelitian ini dilaksanakan pada semester ganjil, selama 4 bulan tahun ajaran 2017/2018. Penelitian yang digunakan adalah penelitian tindakan kelas, karena peneliti terlibat langsung dalam proses penelitian mulai dari awal sampai berakhirnya penelitian.Penelitian tindakan kelas ini didesain mengikuti model Kemmis dan Mc Taggart (dalam Zainal Aqib, 2006: 23) yang dilaksanakan dalam setiap siklus adalah sebagai berikut:

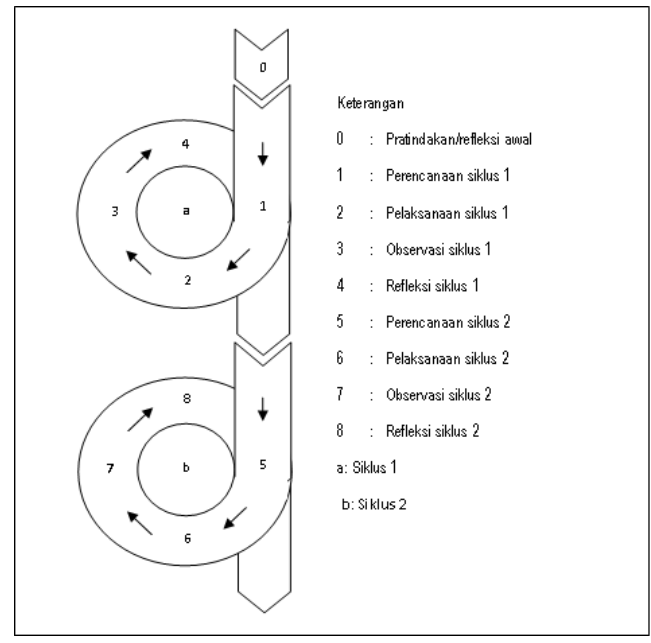

\section{Gambar 1 Model Kemmis dan Mc Taggart (dalam Zainal Aqib, 2006: 23)}

Penelitian ini akan diakukan dengan beberapa prosedur antara lain: tahap perencanaan, tahap pelaksanaan tindakan, tahap pengamatan, dan tahap analisis dan refleksi. Indikator keberhasilan tindakan yang di gunakan untuk mengukur keberhasilan Penelitian Tindakan Kelas adalah: 1) Minimal 75\% aspek-aspek kegiatan guru dalam menerapkan Reggio Emilia Aproach memperoleh skor atau nilai pengamatan dengan kategori baik dan sangat baik. 2) Minimal 75\% aspek-aspek kegiatan anak dalam proses pembelajaran memperoleh skor atau nilai pengamatan dengan kategori baik dan sangat baik. 3) Minimal 75\% dari seluruh anak yang memperoleh tindakan mencapai hasil kecerdasan sosial minimal dengan skor 75 . 
Minimal 75\% dari seluruh anak yang memperoleh tindakan mencapai hasil kecerdasan emosional minimal dengan skor 75.

\section{Hasil Penelitian}

Penerapan metode pembelajaran Regio Emilia Aproach dapat memudahkan kinerja guru karena anak dapat belajar dengan baik serta mampu meningkatkan Kecerdasan Sosial dan Kecerdasan Emosional anak.

Sebagaimana hasil pengamatan pada kegiatan pengelolaan pembelajaran (siklus I), bahwa akumulasi kriteria sangat baik dan baik mencapai $67 \%$, dan pada siklus II meningkat menjadi 80\%.Untuk lebih jelasnya mengenai data ini.

\section{Hasil}

Hasil Penelitian dalam penelitian ini dapat disajikan dalam table berikut ini:

Tabel 1 Pengelolaan Pembelajaran Siklus I dan II

\begin{tabular}{rlcccc}
\hline \multirow{2}{*}{ No } & Kriteria Aspek & \multicolumn{2}{c}{ Jumlah Aspek } & \multicolumn{2}{c}{ Persentase (\%) } \\
\cline { 3 - 6 } & & Siklus I & Siklus II & Siklus I & Siklus II \\
$\mathbf{1}$ & Sangat Baik & 3 & 5 & $20 \%$ & $33 \%$ \\
$\mathbf{2}$ & Baik & 7 & 7 & $47 \%$ & $47 \%$ \\
$\mathbf{3}$ & Cukup & 3 & 2 & $20 \%$ & $13 \%$ \\
$\mathbf{4}$ & Kurang & 2 & 1 & $13 \%$ & $7 \%$ \\
& Jumlah & $\mathbf{1 5}$ & $\mathbf{1 5}$ & $\mathbf{1 0 0 \%}$ & $\mathbf{1 0 0 \%}$ \\
\hline
\end{tabular}

Aspek aktivitas guru

Selain aspek pengelolaan pembelajaran yang menjadi aspek utama dalam mencapai keberhasilan anak dalam belajar, terdapat aspek lain yang tidak kalah pentingnya dalam proses pembelajaran yaitu aktifitas guru dalam setiap siklus pembelajaran. Mengenai kegiatan guru pada metodeRegio Emilia Aproach(siklus I), akumulasi kriteria sangat baik dan baik memperoleh 61\%. Nilai ini mengalami peningkatan pada pelaksanaan siklus II, menjadi 84\%.Untuk lebih jelasnya data tersebut dapat dilihat pada tabel 4.49 berikut.

Tabel 2 Pengamatan Aktivitas Guru Siklus I dan II

\begin{tabular}{llll}
\hline No & Kriteria Aspek Jumlah Aspek & Persentase (\%)
\end{tabular}




\begin{tabular}{cccccc}
\hline & & Siklus I & Siklus II & Siklus I & Siklus II \\
$\mathbf{1}$ & Sangat Baik & 5 & 5 & $38 \%$ & $38 \%$ \\
$\mathbf{2}$ & Baik & 3 & 6 & $23 \%$ & $46 \%$ \\
$\mathbf{3}$ & Cukup & 3 & 1 & $23 \%$ & $8 \%$ \\
$\mathbf{4}$ & Kurang & 2 & 1 & $15 \%$ & $8 \%$ \\
& Jumlah & $\mathbf{1 3}$ & $\mathbf{1 3}$ & $\mathbf{1 0 0 \%}$ & $\mathbf{1 0 0 \%}$ \\
\hline
\end{tabular}

Aktivitas anak

Demikian halnya dengan aktivitas belajar anak, juga mengalami peningkatan.Dimana pada pelaksanaan tindakan siklus I, akumulasi kriteria sangat baik dan baik hanya memperoleh 60\%.Angka ini mengalami peningkatan pada pelaksanaan tindakan siklus II, yakni menjadi $80 \%$.Untuk lebih jelasnya mengenai hal ini dapat dilihat pada tabel 4.50 berikut.

Tabel 3 Aktivitas Anak Siklus I dan II

\begin{tabular}{lccccc}
\hline \multirow{2}{*}{ No } & Kriteria Aspek & \multicolumn{2}{c}{ Jumlah Aspek } & \multicolumn{2}{c}{ Persentase (\%) } \\
\cline { 3 - 6 } & & Siklus I & Siklus II & Siklus I & Siklus II \\
$\mathbf{1}$ & Sangat Baik & 2 & 2 & $20 \%$ & $20 \%$ \\
$\mathbf{2}$ & Baik & 4 & 7 & $40 \%$ & $70 \%$ \\
$\mathbf{3}$ & Cukup & 3 & 1 & $30 \%$ & $10 \%$ \\
$\mathbf{4}$ & Kurang & 1 & 0 & $10 \%$ & $0 \%$ \\
& Jumlah & $\mathbf{1 0}$ & $\mathbf{1 0}$ & $\mathbf{1 0 0} \%$ & $\mathbf{1 0 0} \%$ \\
\hline
\end{tabular}

Kecerdasan sosial anak

Sementara untuk pencapaian Kecerdasan Sosial anak pada gerak tari kreasi dengan menggunakan metodepembelajaran Regio Emilia Aproach diperoleh gambaran sebagaimana terlihat pada tabel 4.51berikut.

Tabel 4 Kecerdasan Sosial Anak Siklus I dan II

\begin{tabular}{cc}
\hline Pembelajaran & Kecerdasan Sosial \\
\cline { 2 - 2 } & Nilai 75 ke atas \\
Siklus I & $55 \%$ \\
Siklus II & $80 \%$ \\
\hline
\end{tabular}


Berdasarkan data tersebut, maka dapat dinyatakan keberhasilan tindakan khususnya pada aspek kecerdasan sosial anak telah mengalami peningkatan dan telah mencapai KKM 75\%.

Hal ini sesuai dengan teori dari Khilstrom dan Cantor dalam Suyono(2007:103) mendefinisikan "kecerdasan sosial sebagai suatu simpanan pengetahuan mengenai dunia sosial, menjalin hubungan dengan orang lain, dan kemampuan dalam menghadapi orang-orang yang berbeda latar belakang dengan cara bijaksana Kecerdasan emosional anak

Sementara untuk pencapaian Kecerdasan Emosional anak pada gerak tari kreasi dengan menggunakan metodepembelajaran Regio Emilia Aproach diperoleh gambaran sebagaimana terlihat pada tabel berikut.

Tabel 5 Kecerdasan Emosional Anak Siklus I dan II

\begin{tabular}{cc}
\hline Pembelajaran & Kecerdasan Emosional \\
\cline { 2 - 2 } & Nilai 75 ke atas \\
Siklus I & $45 \%$ \\
Siklus II & $85 \%$ \\
\hline
\end{tabular}

\section{Diskusi}

Berdasarkan data tersebut, maka dapat dinyatakan keberhasilan tindakan khususnya pada aspek kecerdasan emosional anak telah mengalami peningkatan dan telah mencapai KKM 75\%. Pendapat yang mendukung kecerdasan emosonal anak juga telah dikaji oleh beberapa ahli antara lain yaitu Howard Gardner (2003:34) bahwa "kecerdasan menyangkut kemampuan menyelesaikan masalah atau produk mode yang merupakan konsekuensi dalam suasana budaya atau masyarakat tertentu".Melalui penerapan regio emilia aproach anak dapat dibimbing secara baik untuk mencapai kecerdasan emosional. dalam kecerdasan emosional terdapat kesadaran, motivasi, empati, dan pengaturan diri dalam mengekspresikan potensi dirinya baik melalui budaya masyarakat tertentu. 


\section{Simpulan}

Pada siklus I, bahwa kecerdasan sosial anak dari 20 orang yang tuntas sebanyak 11 orang atau $55 \%$ dan yang belum tuntas adalah 9 orang atau $45 \%$, sedangkan pada aspek kecerdasan emosional anak yang dikatakan tuntas sebanyak 9 orang atau 45\% dan yang belum tuntas adalah 11 orang atau 55\%.

Pada siklus II, dapat disimpulkan bahwa kecerdasan sosial anak dari 20 orang yang tuntas sebanyak 16 orang atau $80 \%$ dan yang belum tuntas adalah 4 orang atau $20 \%$, sedangkan pada aspek kecerdasan emosional anak dari 20 orang yang tuntas sebanyak 17 orang atau 85\% dan yang belum tuntas adalah 3 orang atau 15\%.

Terjadi peningkatan persentase (\%) keberhasilan dari siklus I kesiklus II khususnya pada aspek kecerdasan sosial anak dari 55\% meningkat menjadi 80\%. Peningkatan terjadi sebesar 25\% setelah melakukan berbagai refleksi tindakan pembelajaran. Sedangkan pada aspek kecerdasan emosional dari siklus I kesiklus II mengalami peningkatan sebesar $30 \%$ yakni dari $55 \%$ menjadi $85 \%$.

\section{Daftar Pustaka (Font Cambria, Ukuran 12, spasi 1)}

Aqib, Zainal. 2006. PenelitianTindakanKelasuntuk Guru. Bandung: YRAMA WIDYA.

Gardner, Howard. 2003. Multiple Intelegences. Terj. Alexander Sindoro. Jakarta: Interaksara.

Juniasih, Indah. 2015. Peningkatan Kreativitas Gerak Melalui Kegiatan Tari Pendikan Berbasis Cerita (TARITA). JurnalPendidikanUsiaDini. Volume 9 Edisi 2, November 2015.

Yulsyofriend.,Yaswinda\&Zulminiati. 2013. Pelaksanaan Model Reggio Emeliopada Pembelajaran Anak Usia Dini diTamanKanak-KanakAssyofa Padang. Pedagogi, JurnalIImiahIlmuPendidikan. Volume XIII No.1 April 2013

Suyono, Hadi. 2007. Sosial Intelligence CerdasMeraihSuksesBersama Orang Lain danLingkungan. Jakarta:Ar-ruzz Media. 